\title{
Nightly sildenafil use after radical prostatectomy has adverse effects on urinary convalescence: Results from a randomized trial of nightly vs on-demand dosing regimens
}

\author{
Matthew Eric Hyndman, MD;* Trinity J. Bivalacqua, MD; ${ }^{\dagger}$ Zhaoyong Feng, MS, ${ }^{\dagger}$ Lynda Z. Mettee, MD; ${ }^{\dagger}$ \\ Li-Meng Su, MD; $;$ Bruce J. Trock, MD; Christian P. Pavlovich, MD
}

*Department of Surgery, Division of Urology, Southern Alberta Institute of Urology, University of Calgary, Calgary, AB; † James Buchanan Brady Urological Institute, Johns Hopkins University, Baltimore, MD; §University of Florida College of Medicine, Gainesville, FL

Cite as: Can Urol Assoc J 2015;9(11-12):414-9. http://dx.doi.org/10.5489/cuai.3169

Published online November 9, 2015.

\section{Abstract}

Introduction: This is a report on potency results from a randomized trial of nightly versus on-demand sildenafil after nerve-sparing radical prostatectomy $(\mathrm{RP})$. A secondary objective was to analyze the effects of these sildenafil administration schemes on urinary health-related quality of life after RP.

Methods: In total, 100 potent men were equally randomized to nightly and on-demand sildenafil $50 \mathrm{mg}$ after minimally-invasive RP for 1 year. Health-related quality of life questionnaires were administered at various postoperative intervals. Urinary function was assessed using appropriate expanded prostate cancer index composite (EPIC) subscales. Analyses of covariance and linear mixed-effects modeling were used to compare the effects of treatment over time on urinary recovery, controlling for age, nervesparing score, and time from surgery.

Results: The nightly $(\mathrm{n}=50)$ and on-demand $(\mathrm{n}=50)$ sildenafil groups were well-matched at baseline. Nightly sildenafil patients had worse EPIC urinary bother and urinary irritative/obstructive subscale scores at 3 and 6 months after RP, even after controlling for multiple variables. On mixed-model analyses, the differences between groups for these EPIC subscales (4.9 and 2.5, respectively) were greater than documented thresholds for clinical significance. Increasing nerve-sparing score was associated with improvements in EPIC urinary summary, bother, incontinence, and function scores; time from surgery was associated with improvements in all EPIC urinary health-related quality of life subscales.

Conclusions: In this specific population and drug dose, we found that on-demand short-acting phosphodiesterase-5 inhibitor (PDE5i) dosing may be more effective after RP to maximize early urinary and erectile health-related quality of life. In preoperatively potent men, nightly sildenafil $50 \mathrm{mg}$ impaired urinary health-related quality of life more than on-demand use in the early months after nerve-sparing RP, independent of effects on urinary continence.

\section{Introduction}

Recovery of urinary continence and potency after radical prostatectomy (RP) are important predictors of postoperative quality of life. Numerous publications have reported varying rates of continence and potency after prostatectomy. ${ }^{1,2}$ The wide divergence of results with respect to continence can be attributed in part to different functional definitions of continence, demographic factors, varied surgical technique, and the time points at which continence status is determined. Reported potency rates after RP are also affected by similar variables, as well by the preoperative potency status and the quality of nerve-sparing performed during surgery.

The use of phosphodiesterase-5 inhibitors (PDE5i) after $\mathrm{RP}$ for penile rehabilitation has been studied in several randomized clinical trials with different reported outcomes. While the major effect of PDE5i is on potency, one of the pleiotropic effects of PDE5i is their ability to improve urinary symptoms in men with lower urinary tract symptoms (LUTS). ${ }^{3}$ Therefore in addition to affecting post-RP potency rates, the use of PDE5i may affect recovery of urinary continence and/or urinary quality of life after RP. ${ }^{4}$ While several randomized controlled trials (RCT) suggest that nightly use of PDE5 $\mathrm{i}$ is no more beneficial than on-demand use in terms of improving long-term erectile function after nerve-sparing $\mathrm{RP},{ }^{5,6}$ many urologists nevertheless still prescribe chronic PDE5i immediately after RP. ${ }^{7}$ The present study is a secondary outcomes analysis from a published randomized clinical trial that compared 2 different dosing regimens of postoperative sildenafil (50 mg nightly vs. $50 \mathrm{mg}$ on-demand) for 1 year after nerve-sparing minimally invasive RP. ${ }^{5}$

In this report, we evaluated the effect of postoperative sildenafil dosing regimens on the temporal recovery of urinary continence and urinary quality of life after nerve-sparing minimally-invasive RP as assessed by urinary subscales of the EPIC questionnaire. 


\section{Methods}

Patients in the present secondary outcomes analysis participated in a single-institution multi-surgeon 100-patient double-blind RCT of nightly versus on-demand $50 \mathrm{mg}$ sildenafil after nerve-sparing minimally invasive RP for prostate cancer. The study protocol has been previously published. ${ }^{5}$ Postoperatively, patients were randomly administered the study drug for 1 year and were divided in 2 groups: (1) The "nightly" group $(\mathrm{n}=50)$ received nightly $50 \mathrm{mg}$ sildenafil dosing, and (2) the "on-demand" group $(\mathrm{n}=50)$ received nightly placebo. Both groups were also given tablets for ondemand use, up to 6 per month. The nightly group received on-demand placebo tablets, while the on-demand group received $50 \mathrm{mg}$ sildenafil, such that no patient was without exposure to PDE5i in the year after minimally invasive RP. Drug use was tracked throughout the trial. Nerve-sparing quality in each case was subjectively graded by the operative surgeon on a 0 (none) to 4 (excellent) scale/neurovascular bundle, resulting in a nerve-sparing score (NSS) of 0 to $8 .{ }^{8}$ Urinary function was initially assessed by the EPIC questionnaire, and then again after RP at 1, 3, 6, 9, 12 months, and after a 1 month PDE5i washout period (13 months postoperatively). Specific EPIC urinary subscales were used for the analyses presented in the current study: urinary domain summary score (USS): urinary irritative/obstructive subscale, also termed urinary irritative subscale (UIR); urinary bother subscale (UBS); urinary incontinence subscale (UIN); and urinary function subscale (UFS), with higher scores representing better health-related quality of life.

Trial design and analysis were as previously published. ${ }^{5}$ Secondary analyses concerning EPIC questionnaire urinary subscales and responses to single items of the various validated instruments were compared between groups at each time point. Analyses were done using analysis of covariance, and overall time points and a linear mixed-effects model with random slopes and intercepts and unstructured variance-covariance matrix. Interactions were modelled as cross-product terms to determine whether the treatment effect differed by treatment group or other variables, including time from surgery, age and NSS. Because some men did not return questionnaires at all time points, we also analyzed data using multiple imputation based on a Markov chain Monte Carlo simulation to impute missing values. All statistical calculations were two-sided and performed with SAS v9.2 (SAS Institute, Cary, NC).

\section{Results}

Patient demographics and group characteristics are listed in Table 1. USS, UIR, UBS, UIN and UFS of the EPIC were compared by treatment group. At baseline there were no significant differences between groups. However, after an initial decline at 1 month in both treatment groups, there was statistically greater improvement in some EPIC urinary measures in the on-demand sildenafil group compared to the nightly sildenafil group. At 3 months and 6 months postoperatively, the EPIC UIR ( $p=0.005)$ and UBS $(p=0.001)$ score significantly increased in the on-demand sildenafil group. There was no difference in any of the EPIC urinary measures between groups beyond 6 months.

The nightly sildenafil group also had significantly worse EPIC outcomes for item 34 ("Overall, how big a problem has your urinary function been for you over the past 4 weeks?"; 5 -point scale with 1 representing "no problem" and 5 representing "big problem"). Answers to item 34 were comparable at baseline (1.1 on-demand vs. nightly $1.4, p=0.7$ ) and at 1 month (3.5 on-demand vs. nightly 3.8, $p=0.2$ ), but patients taking nightly sildenafil reported more dissatisfaction compared to the on-demand patients at 3 months (2.2 on-demand vs. 3.0 nightly, $p=0.001), 6$ months $(1.7$ on-demand vs. 2.4 nightly, $p=0.025)$, and 9 months $(1.6$ on-demand vs. 2.2 nightly, $p=0.021$ ) after RP. Any difference was lost after the 9-month time point. Pad use was similar across groups, though there was higher mean pad use in the nightly sildenafil group at postoperative month 9 (EPIC item 27, $p=0.02$ ).

\begin{tabular}{|c|c|c|c|}
\hline Characteristic & $\begin{array}{l}\text { Nightly } \\
\text { sildenafil }\end{array}$ & $\begin{array}{c}\text { On- } \\
\text { demand } \\
\text { sildenafil }\end{array}$ & $\begin{array}{c}p \\
\text { value }\end{array}$ \\
\hline $\begin{array}{l}\text { Age, mean (median) } \\
\text { Range }\end{array}$ & $\begin{array}{l}54.3(55) \\
(42-63)\end{array}$ & $\begin{array}{l}53.6(54) \\
(40-64)\end{array}$ & 0.520 \\
\hline $\begin{array}{l}\text { Race, n (\%) } \\
\text { White } \\
\text { Non-white }\end{array}$ & $\begin{array}{l}45(90) \\
5(10)\end{array}$ & $\begin{array}{l}44(88) \\
6(12)\end{array}$ & 0.749 \\
\hline $\begin{array}{l}\text { Baseline IIEF-EF score (mean) } \\
\text { Range }\end{array}$ & $\begin{array}{l}29.4(30) \\
(26-30)\end{array}$ & $\begin{array}{l}29.3(30) \\
(26-30)\end{array}$ & 0.493 \\
\hline $\begin{array}{l}\text { Clinical stage, number }(\%) \\
\text { T1c } \\
\text { T2a }\end{array}$ & $\begin{array}{l}37(74) \\
13(26)\end{array}$ & $\begin{array}{l}40(80) \\
10(20)\end{array}$ & 0.614 \\
\hline $\begin{array}{l}\text { Biopsy Gleason score }(n, \%) \\
6 \\
7\end{array}$ & $\begin{array}{c}41(82 \%) \\
9(18 \%)\end{array}$ & $\begin{array}{c}42(84 \%) \\
8(16 \%)\end{array}$ & 0.790 \\
\hline $\begin{array}{l}\text { Preoperative PSA, mean (median) } \\
\text { Range }\end{array}$ & $\begin{array}{l}4.7(4.4) \\
(0.6-14)\end{array}$ & $\begin{array}{l}5.1(5.1) \\
(0.8-9.0)\end{array}$ & 0.307 \\
\hline $\begin{array}{l}\text { Type of RP surgery, n (\%) } \\
\text { Laparoscopic } \\
\text { Robotic-assisted laparoscopic }\end{array}$ & $\begin{array}{l}40(80) \\
10(20)\end{array}$ & $\begin{array}{l}37(74) \\
13(26)\end{array}$ & 0.476 \\
\hline $\begin{array}{l}\text { NVB preserved, n (\%) } \\
1 \\
2\end{array}$ & $\begin{array}{c}1(2) \\
49(98)\end{array}$ & $\begin{array}{c}1(2) \\
49(98)\end{array}$ & 1.00 \\
\hline $\begin{array}{l}\text { Nerve-sparing score* mean } \\
\text { (median) } \\
\text { Range }\end{array}$ & $\begin{array}{c}6.5(6) \\
(2-8)\end{array}$ & $\begin{array}{l}7.1(8) \\
(3-8)\end{array}$ & 0.033 \\
\hline
\end{tabular}

RP: radical prostatectomy; IIEF-EF: PSA: prostate-specific antigen; *Nerve-sparing score is a sum of the scores for right and left neurovascular bundle preservation quality, each individually graded by the attending surgeon on a $0-4$ scale.21 
Hyndman et al.

Mixed model analysis assessing the effect of nightly and on-demand sildenafil dosing across all time points also suggested that the UBS $(p=0.021)$ and UIR $(p=0.036)$ were significantly lower. This indicated a worse health-related quality of life in the nightly sildenafil group after adjusting for age, NSS (categorical or binary) and postoperative time point (Table 2, Fig 1, Fig. 2).

Patients taking nightly sildenafil averaged a 4.9-unit lower UBS score and a 2.5-unit lower UIR score compared to the on-demand group over the first year after RP. Mixed linear regression did not show a statistically significant difference between the nightly and on-demand sildenafil groups in the other EPIC urinary subscales UIN, UFS, USS or in pad usage (Table 2). Increasing NSS, a continuous measure of nervesparing quantity and quality, was associated with improvements in all EPIC urinary-specific health-related quality of life outcomes, except in the UIR scores.

\section{Discussion}

In this blinded, randomized, controlled study, we showed that patients receiving nightly sildenafil have significantly worse EPIC UBS and UIR compared to patients using ondemand sildenafil during their post-prostatectomy convalescence. In general, the use of chronic nightly sildenafil had a deleterious effect on early urinary health-related quality of life, primarily regarding urinary irritation and bother, and overall satisfaction with urinary function. These effects on EPIC urinary subscale scores were not only statistically, but clinically, significant, with mean differences of 2.5 and 4.9, well over the 1.0 to 1.6 threshold for clinical significance on the various subscales recently noted by the PROST-QA (Prostate Cancer Outcomes and Satisfaction with Treatment Quality Assessment). ${ }^{9}$ This deleterious effect persisted despite controlling for factors known to affect urinary con-

\begin{tabular}{|c|c|c|c|}
\hline EPIC interest variable & Variables in model & Slope* & $p$ value \\
\hline \multirow{5}{*}{$\begin{array}{l}\text { Urinary summary } \\
\qquad \mathrm{n}=467 \\
\text { Mean }=76.8 \\
\text { Median }=81.9 \\
\text { Range }=15.2-100.0\end{array}$} & Nightly vs. on-demand sildenafil & -2.8 & 0.156 \\
\hline & Postoperative time point & 1.5 & $<0.0001$ \\
\hline & NSS & 2.5 & 0.001 \\
\hline & Age & -0.3 & 0.054 \\
\hline & Urinary summary score (month 0 ) & 0.1 & 0.406 \\
\hline \multirow{5}{*}{$\begin{array}{l}\text { Urinary bother } \\
\qquad \begin{array}{l}\mathrm{N}=466 \\
\text { Mean }=79.7 \\
\text { Median }=85.7 \\
\text { Range }=14.3-100.0\end{array}\end{array}$} & Nightly vs. on-demand sildenafil & -4.9 & 0.021 \\
\hline & Postoperative time point & 2.3 & $<0.0001$ \\
\hline & NSS & 1.9 & 0.015 \\
\hline & Age & -0.2 & 0.245 \\
\hline & Urinary bother subscale (month 0 ) & 0.1 & 0.306 \\
\hline \multirow{5}{*}{$\begin{array}{l}\text { Urinary irritative } \\
\qquad \begin{array}{l}\mathrm{N}=467 \\
\text { Mean }=88.5\end{array} \\
\text { Median }=92.8 \\
\text { Range }=17.8-100.0\end{array}$} & Nightly vs. on-demand sildenafil & -2.5 & 0.036 \\
\hline & Postoperative time point & 0.8 & $<0.0001$ \\
\hline & NSS & 0.5 & 0.292 \\
\hline & Age & -0.06 & 0.551 \\
\hline & Urinary irritative subscale (Month 0) & 0.2 & 0.003 \\
\hline \multirow{5}{*}{$\begin{array}{l}\text { Urinary incontinence } \\
\qquad \begin{array}{l}\mathrm{N}=467 \\
\text { Mean }=58.9 \\
\text { Median }=58.5 \\
\text { Range }=0-100.0\end{array}\end{array}$} & Nightly vs. on-demand sildenafil & -0.2 & 0.948 \\
\hline & Postoperative time point & 2.9 & $<0.0001$ \\
\hline & NSS & 5.2 & $<0.0001$ \\
\hline & Age & -0.3 & 0.252 \\
\hline & Urinary incontinence subscale (month 0 ) & 0.05 & 0.775 \\
\hline \multirow{5}{*}{$\begin{array}{l}\text { Urinary function } \\
\quad \mathrm{N}=470 \\
\text { Mean }=72.6 \\
\text { Median }=73.4 \\
\text { Range }=11.6-100.0\end{array}$} & Nightly vs. on-demand sildenafil & -0.2 & 0.920 \\
\hline & Postoperative time point & 2.0 & $<0.0001$ \\
\hline & NSS & 3.7 & $<0.0001$ \\
\hline & Age & -0.3 & 0.132 \\
\hline & Urinary function subscale (month 0) & 0.2 & 0.226 \\
\hline \multirow{5}{*}{$\begin{array}{l}\text { Pad usage } \\
\mathrm{N}=470 \\
\text { Mean }=1.0 \\
\text { Median }=1 \\
\text { Range }=0-3\end{array}$} & Nightly vs. on-demand sildenafil & 0.04 & 0.734 \\
\hline & Postoperative time point & -0.1 & $<0.0001$ \\
\hline & NSS & -0.2 & 0.005 \\
\hline & Age & 0.02 & 0.012 \\
\hline & Pad usage (Month 0) & - & - \\
\hline
\end{tabular}




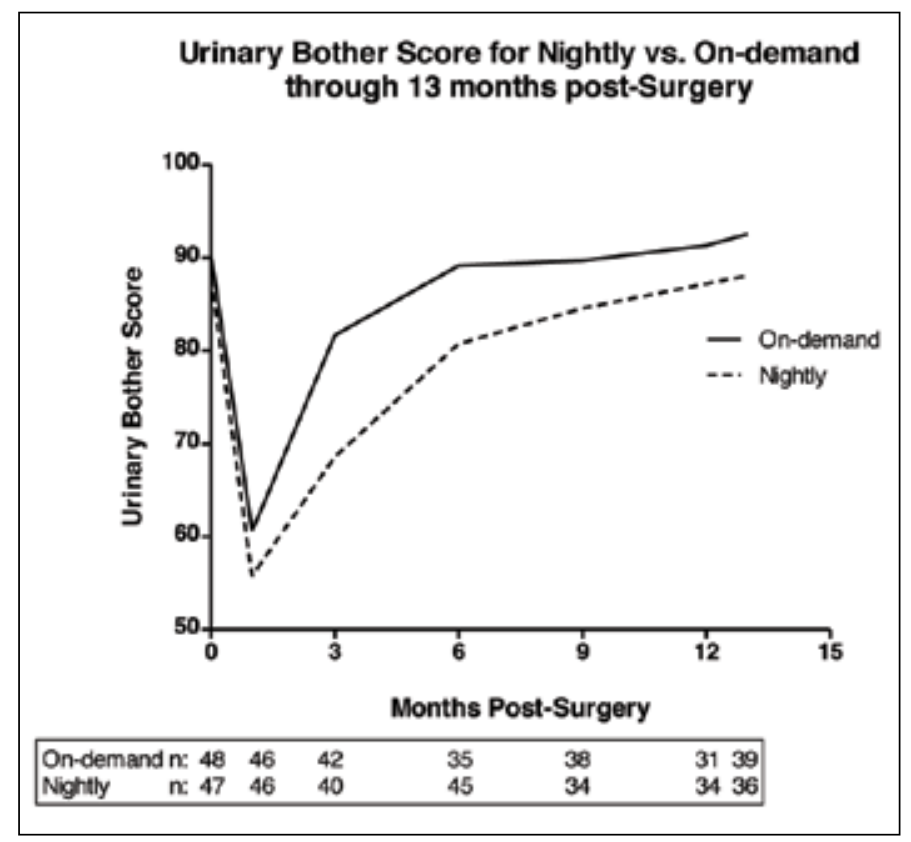

Fig. 1. Mean urinary bother scores (UBS) plotted from baseline to washout stratified by nightly vs. on demand sildenafil $50 \mathrm{mg}$ dosing (mixed linear analysis with adjustment for age, nerve-sparing score and time point; UBS $p=0.021$ ).

valescence, including age, nerve-sparing quality/quantity as captured by nerve-sparing score (NSS), and time after surgery. While the effects of better nerve-sparing on improving early urinary outcomes after RP in previously potent men have been suggested in the literature, ${ }^{10-12}$ it has not been shown that early PDE5i use after RP may adversely affect early urinary health-related quality of life.

It is known that PDE5i therapy improves erections during the convalescence from nerve-sparing $R P{ }^{13}$ its effects on penile rehabilitation with daily use after RP are less clear. A number of RCTs have reported on the effects of daily PDE5i use on postoperative erectile function with discordant results..$^{5,6,14,15}$ In addition, there is strong evidence demonstrating that PDE5i affect and improve LUTS. ${ }^{16}$ Moreover, an association between LUTS and erectile dysfunction has been clearly established, and recently reviewed by Mouli and McVary. ${ }^{17}$

Gacci and colleagues reported a small three-armed study that was similar to ours, using daily vardenafil, on-demand vardenafil, and a placebo group. ${ }^{4}$ Based on this trial with only 12 to 14 patients per arm, the authors suggested that daily vardenafil use improved postoperative continence as determined by the UCLA-PCI (University of CaliforniaLos Angeles Prostate Cancer Index). The authors reported improvements in urinary function and bother in patients taking nightly vardenafil compared to those taking it ondemand or taking placebo during the months after RP. ${ }^{4}$ However, this improvement was entirely dependent on a significantly greater initial decline in urinary function and

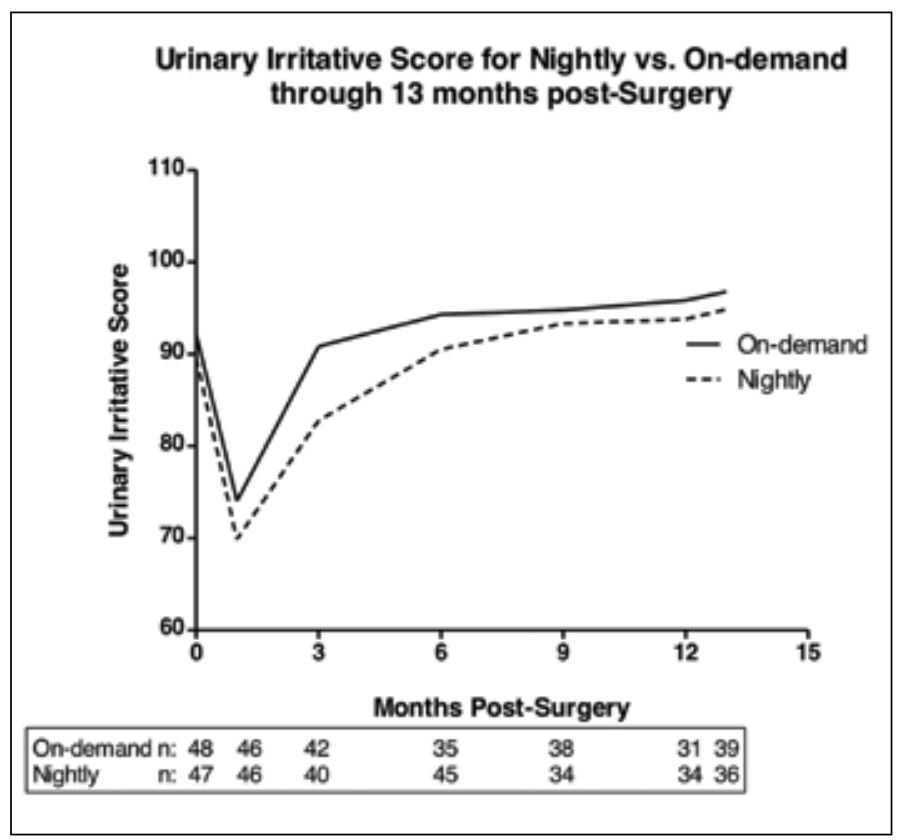

Fig. 2. Mean urinary irritative score (UIR) plotted from baseline to washout stratified by nightly vs. on demand sildenafil $50 \mathrm{mg}$ dosing (mixed linear analysis with adjustment for age, nerve-sparing score and time point; UIR $p=0.036$ ).

bother in the nightly vardenafil group, and a subsequent improvement from that state of decreased urinary function over time. Indeed by 12 months, urinary outcomes were equivalent in all groups, so another interpretation of their data is that nightly vardenafil delays urinary recovery until the first postoperative year.

In our larger cohort, we found that nightly sildenafil also contributed to a significant decline in aspects of urinary health-related quality of life after RP, specifically in the EPIC UIS and UBS (irritation and bother subscales) compared to the on-demand group after RP (Fig. 1, Fig. 2). Together these studies suggest that chronic use of short-acting postoperative PDE5i impairs early urinary health-related quality of life, perhaps by affecting bladder neck contractility/sensitivity or urethral tone. This difference is less pronounced over time, as continence, bother and irritation improve naturally after surgery. Interestingly, the greatest difference between groups was evident during the early recovery phase in both our sildenafil study (Fig. 1, Fig. 2) and in the vardenafil trial by Gacci and colleagues. ${ }^{4}$ It certainly is possible that there are differences between the effects of sildenafil and vardenafil on urinary convalescence after RP, but the similar data that resulted from our study, the Gacci study and previous reports using short-acting PDE5i post-RP all suggest that these drugs act very similarly in this setting. ${ }^{18}$

Pertinently, Bittencourt and colleagues recently demonstrated that sildenafil relaxes human bladder tissue depending on the nitric oxide/cGMP pathway. ${ }^{16}$ It is possible that relaxation of bladder neck tissue facilitated by sildenafil 
Hyndman et al.

impairs early urinary function after RP. With time, and as the external sphincter strengthens, this effect may become less pronounced. We did not find a significant association between nightly dosing and urinary incontinence subscale scores (UIN), which raises the possibility that sildenafil could be acting through a mechanism mediated by sensory pathways rather than directly via smooth muscle relaxation. This may account for the stronger association between nightly use and the bother/irritative EPIC domains (UBS and UIR). Alternatively, this study may be underpowered to detect small differences across all time points with respect to urinary incontinence, although we did find some differences along individual time points in favour of on-demand rather than nightly use as regards early return of continence.

Our finding of increased bother associated with daily use is also indirectly supported by accumulating evidence that PDE5i are associated with relief of symptomatic LUTS. ${ }^{3,19}$ In a multicentre randomized double-blinded study, Dmochowski and colleagues ${ }^{20}$ found that tadalafil did not affect urodynamic parameters, but did improve both obstructive and irritative IPSS domains. Given the relatively strong evidence that PDE5i improves LUTS, it is not entirely surprising that nightly sildenafil in our study negatively affected early urinary functional recovery after RP.

Since sildenafil nightly use was not associated with a significant early or late improvement in erectile function in preoperatively potent men (the primary outcome of this RCT), ${ }^{5}$ we feel that the present urinary outcomes data support on-demand rather than nightly/chronic use of shortacting PDE5i in such patients in the early post-prostatectomy setting. There are limitations inherent to our study, as the effect of only 1 drug at 1 dose was evaluated. In addition, despite being one of the only randomized trials examining the effect of PDE5i on urinary incontinence, randomization and other biases are still possible in this 100-patient study. Therefore extrapolation of our findings to other populations and drugs must be undertaken with some degree of caution, and confirmation of our findings in larger trials is warranted. Finally, our results are secondary outcomes and the trial was not powered specifically with these in mind. Nevertheless, both statistically and clinically significant findings involving urinary health-related quality of life were demonstrated, rendering any discussion of trial power relevant only to the urinary subscales unaffected by PDE5i dosing regimen in this study.

\section{Conclusions}

In a randomized controlled study, nightly use of sildenafil was associated with decreased urinary function scores using the EPIC questionnaire. These findings were primarily noted early in the recovery phase after RP and mainly affected the urinary irritative and urinary bother subscales of the EPIC health-related quality of life instrument. Further studies are warranted to confirm our findings. Currently, we recommend an on-demand, rather than a nightly, approach to PDE5i use to avoid deleterious effects on urinary healthrelated quality of life in the early months after nerve-sparing $\mathrm{RP}$, with support for erectile function recovery.

Competing interests: Funding for this project was provided by Pfizer.

This paper has been peer-reviewed.

\section{References}

1. Penson DF, Feng Z, Kuniyuki A, et al. General quality of life 2 years following treatment for prostate cancer: what influences outcomes? Results from the prostate cancer outcomes study. J Clin Oncol 2003;21:114754. http://dx.doi.org/10.1200/JC0.2003.07.139

2. Sanda MG, Dunn RL, Michalski J, et al. Quality of life and satisfaction with outcome among prostatecancer survivors. N Engl J Med 2008;358:1250-61. http://dx.doi.org/10.1056/NEJMoa074311

3. Stief $C G$, Porst $H$, Neuser $D$, et al. A randomised, placebo-controlled study to assess the efficacy of twicedaily vardenafil in the treatment of lower urinary tract symptoms secondary to benign prostatic hyperplasia. Eur Urol 2008;53:1236-44. http://dx.doi.org/10.1016/j.eururo.2008.01.075

4. Gacci $M$, lerardi A, Rose AD, et al. Vardenafil can improve continence recovery after bilateral nerve sparing prostatectomy: Results of a randomized, double blind, placebo-controlled pilot study. J Sex Med 2010;7:234-43. http://dx.doi.org/10.1111/i.1743-6109.2009.01471.x

5. Pavlovich CP, Levinson AW, Su LM, et al. Nightly vs on-demand sildenafil for penile rehabilitation after minimally invasive nerve-sparing radical prostatectomy: Results of a randomized double-blind trial with placebo. BJU Int 2013;112:844-51. http://dx.doi.org/10.1111/bju.12253

6. Montorsi $F$, Brock $G$, Lee J, et al. Effect of nightly versus on-demand vardenafil on recovery of erectile function in men following bilateral nerve-sparing radical prostatectomy. Eur Urol 2008;54:924-31. http:// dx.doi.org/10.1016/i.eururo.2008.06.083

7. Tal R, Teloken P, Mulhall JP. Erectile function rehabilitation after radical prostatectomy: Practice patterns among AUA members. J Sex Med 2011;8:2370-6. http://dx.doi.org/10.1111/i.17436109.2011.02355.x

8. Levinson AW, Pavlovich CP, Ward NT, et al. Association of surgeon subjective characterization of nerve sparing quality with potency following laparoscopic radical prostatectomy. J Urol 2008;179:1510-4. http://dx.doi.org/10.1016/i.juro.2007.11.064

9. Chipman JJ, Sanda MG, Dunn RL, et al. Measuring and predicting prostate cancer related quality of life changes using EPIC for clinical practice. J Urol 2014;191:638-45. http://dx.doi.org/10.1016/i. juro.2013.09.040

10. Steineck G, Biartell A, Hugosson J, et al. Degree of preservation of the neurovascular bundles during radical prostatectomy and urinary continence 1 year after surgery. Eur Urol 2015;67:559-68. http:// dx.doi.org/10.1016/i.eururo.2014.10.011

11. Kaye DR, Hyndman ME, Segal RL, et al. Urinary outcomes are significantly affected by nerve sparing quality during radical prostatectomy. Urology 2013;82:1348-53. http://dx.doi.org/10.1016/i.urology.2013.06.067

12. Reeves F, Preece P, Kapoor J, et al. Preservation of the neurovascular bundles is associated with improved time to continence after radical prostatectomy but not long-term continence rates: Results of a systematic review and meta-analysis. Eur Urol 2015;68:692-704. http://dx.doi.org/10.1016/i. eururo.2014.10.020. Epub 2014 0ct 29.

13. Magheli A, Burnett AL. Erectile dysfunction following prostatectomy: Prevention and treatment. Nat Rev Urol 2009;6:415-27. http://dx.doi.org/10.1038/nrurol.2009.126

14. Padma-Nathan $H, M c C$ Cullough AR, Levine LA, et al. Randomized, double-blind, placebo-controlled study of postoperative nightly sildenafil citrate for the prevention of erectile dysfunction after bilateral nerve-sparing radical prostatectomy. Int J Impot Res 2008;20:479-86. http://dx.doi.org/10.1038/iiir.2008.33 
15. Montorsi F, Brock G, Stolzenburg JU, et al. Effects of tadalafil treatment on erectile function recovery following bilateral nerve-sparing radical prostatectomy: A randomised placebo-controlled study (REACTT). Eur Urol 2014;65:587-96. http://dx.doi.org/10.1016/i.eururo.2013.09.051

16. Bittencourt JA, Tano T, Gajar SA, et al. Relaxant effects of sildenafil on the human isolated bladder neck. Urology 2009;73:427-30. http://dx.doi.org/10.1016/j.urology.2008.06.060

17. Mouli S, McVary KT. PDE5 inhibitors for LUTS. Prostate Cancer and Prostatic Dis 2009;12:316-24. http:// dx.doi.org/10.1038/pcan.2009.27

18. Nehra A, Grantmyre J, Nadel A, et al. Vardenafil improved patient satisfaction with erectile hardness, orgasmic function and sexual experience in men with erectile dysfunction following nerve sparing radical prostatectomy. J Urol 2005;173:2067-71. hitp://dx.doi.org/10.1097/01.ju.0000158456.41788.93
19. McVary KT, Roehrborn CG, Kaminetsky JC, et al. Tadalafil relieves lower urinary tract symptoms secondary to benign prostatic hyperplasia. J Urol 2007;177:1401-7. http://dx.doi.org/10.1016/i.juro.2006.11.037

20. Dmochowski R, Roehrborn C, Klise S, et al. Urodynamic effects of once daily tadalafil in men with lower urinary tract symptoms secondary to clinical benign prostatic hyperplasia: A randomized, placebo controlled 12-week clinical trial. J Urol 2010;183:1092-7. http://dx.doi.org/10.1016/i.juro.2009.11.014

Correspondence: Dr. Matthew Eric Hyndman, Department of Surgery, Division of Urology, Southern Alberta Institute of Urology, University of Calgary, Calgary, AB; erichyndman@shaw.ca 